\title{
HUMAN RESOURCES MONITORING AND DEVELOPMENT
}

\section{Rodica DRAGOMIROIU, Iulian HURLOIU, Bianca RUSU, Elena BURTEA}

\author{
"Spiru Haret" University, Bucharest, Romania \\ rodica.dragomiroiu@yahoo.com, iulian.hurloiu@spiruharet.ro, \\ bianca_preda1974@yahoo.com, elenapana2006@yahoo.com
}

\begin{abstract}
Performance management in organizations is mainly concentrated on evaluating employees' results and on rewards. The efficient work of a member of an organization is usually seen as a consequence of the interactions between individual skills and motivation. More and more managers of successful business organizations recognize the critical importance of planning and monitoring the employees' work results.
\end{abstract}

Keywords: management, monitoring, monitoring systems, performance management, employees' performance

Traditional employee monitoring systems have created uniform processes based on which their results could be analyzed. These were centralized processes, usually in the function of human resources and each manager was required to assess the performance of all employees who were his subordinates. These assessments usually took place once a year, usually at the end. This called for managers and employees to attend meetings where they discussed the results of their work. Usually, these meetings have led to employee performance monitoring means that were not documents which could be constantly updated. Usually, they were archived within the human resources department and their content was used only at the next meeting where results were evaluated.

By using quantitative and qualitative indicators, various items were monitored and evaluated, usually covering the employee's personality, behavior and performance at work. Qualitative indicators usually contain an unstructured narrative description of the overall results of the employee, along with some discussion topics that were mentioned during the performance evaluation. The problem with evaluating work quality was reflected in the fact that there has always been a very high probability that some areas of importance could be omitted, while the biggest drawback was that this method was not suitable for any type of comparison.

What is really measured when assessing and monitoring the results of employees is the degree to which they have adapted to the organization. Traditional employee performance evaluation was based on an estimate of parameters that managers considered important for task performance at a specific job. It also included indicators such as intelligence, abilities, motivation, responsibility, enthusiasm, work knowledge etc.

The main problem in all this was reflected in the fact that each person interprets the values of these indicators in different ways, which caused the 
performance review of employees to be influenced by several factors, such as attitudes or prejudices of managers that have significantly affected the results. Another problem has reflected in the fact that the same scales were used for different tasks, which often led to completely wrong results, because the importance of parameters differs from one job to another. The other approaches have correlated the employee behavior with the results obtained in the workplace. Thus, the work results were comparable to key aspects of the job or to main tasks available in the description of each job.

Another method that has led to a more objective monitoring and evaluation was to use the job goals setting process for next year, that could generate a parameter for assessing the extent to which these objectives have been achieved during the monitored period. The degree to which the person whose activity is evaluated is included in the process of setting these targets varies considerably.

Once the skills profile is created for a specific job (which the executive should have), it becomes a useful tool in evaluating the results of that person. Numerous systems for assessing and monitoring work results use the combination of skills assessment and evaluation of the degree of achieving objectives.

The results of one's work can be evaluated and monitored by collecting primary data with the help of a number of different forms of modern electronic monitoring systems. There are numerous ways to monitor and analyze the performance of computer operators or the calls of telemarketing services operators. It comes as interesting the example of a Japanese factory which produces electronic components where the final test of the finished product is done on a device that, besides visible errors, automatically identifies the workplace, the person who experienced the error. On the other hand, for example, it is increasing in popularity the concept with the help of which companies check the working manner of the sales staff by sending 'false' buyers whose task is to monitor the sellers' work and behavior. Some research conducted in the last five years in the US have reached to the conclusion that around $95 \%$ of medium and large companies have developed systems to monitor employees' work results, and most of them (91\%) have developed these systems for all employees.

Despite the fact that such systems are becoming more widespread and allow the monitoring of all employees' work, not just managers, there is a certain amount of concern because they are treated as an administrative exercise, that they are inefficient and do not provide significant improvement of the results of the employees' work in the long run.

The added disadvantage of these systems is also reflected in the significant lack of clarity of their intention. It often gets to the situation where the systems for monitoring employees' work results do not meet or emit unrealistic expectations. Systems can focus on development, on identifying future potentials, on reward, on identifying the individual or the parts of the organization that generate poor results, on employee motivation etc.

In systems where work evaluation results are directly related to payments and other benefits that employees receive, managers are the ones who make the final decision on this. Some systems for assessing and monitoring employees' results, which are used most often in the public sector, are targeted towards providing support or development. These systems offer managers a better opportunity to provide constructive feedback to employees, and employees are provided with a channel through which the can communicate openly with managers about problems they encounter in their work.

In practice, most often encountered are systems that represent a compromise between the two mentioned approaches. A 
research conducted in the US in 2005, led to the conclusion that $92 \%$ of companies use systems to monitor employees' work in order to confirm the needs for training and development of employees (mostly formal), $65 \%$ used systems, formally or informally, in order to determine salaries, while $43 \%$ of companies used these systems for determining bonuses, formally or informally. Because these two approaches are conflicting to a significant extent, the results obtained in this way were often unsatisfactory.

The effectiveness of the system for monitoring employees' work depends on many different factors.

Three of the most important reasons for which these systems do not provide satisfactory results in practice are:

- unclear criteria for assessing the performance or the use of inefficient tools for evaluation

- bad relations between employees and managers

- the person who monitors and evaluates the work does not have enough relevant data to enable the assessment in an objective manner.

The main problem of systems for monitoring employees' work lies not only in their weak design and implementation, but it is also reflected in the reactions of the organization's members on this concept. Settlement of employees' mistrust and their negative attitude towards the monitoring and evaluation of work results represents the most important prerequisite for effective implementation of these systems in everyday work processes of organizations.

As we know, the systems for monitoring and evaluating employees' work are still used in most organizations. Despite their continuous improvement, numerous disadvantages that accompany them have led to the need to develop new solutions that will ensure an easier and more efficient work on tasks of employees monitoring results. As a result of these needs, in the past two decades they have begun to implement employees' work results management systems which slowly begin to take preeminence in management tasks for employees' work performance. These systems, as part of the management of the employees' results, include evaluation processes and performance monitoring of their work.

To understand how these systems function it is primarily necessary to define the concept of employee performance management. Clark defined employee performance management by highlighting the basis of this process: employee performance management represents setting the framework in which they can direct the performance of human resources within the organization, which can monitor, direct and motivate their work.

After the research carried out in 1992, Bevan and Thompson concluded that at that time $20 \%$ of organizations whose work they have analyzed, had already introduced a system for employee performance management. In 1998, Armstrong and Baron ${ }^{2}$ reported that $69 \%$ of the companies that they've studied in 1997 had defined a formal process for measuring managers' performance. These systems are usually closely linked with the objectives of the organization as a whole, leading to the fact that the results that the managers will get will coincide with a much greater probability with the needs of the organization.

Employee performance management systems also present a holistic view on performance. Evaluating employee performance is always a key component of employee performance management systems, but in these systems performance planning is integrated, which link individual employee goals with the organization's business goals. In this way it is assured that the efforts of employees are directed to the organization's priorities: support for the delivery of work results (through development plans, training, coaching and continuous checks and analyzes of 
employees' work results) in order to ensure the success of the efforts of employees, and that work results are assessed objectively, together with reward and encouraging performance.

The conceptual basis of employee performance management systems is the premise that the work results are more important than skills and motivation. Clarity of the set objectives is a key factor for the employees to understand what is expected of them and what the priority of the tasks assigned to them is.

Goals should also be a very strong means for motivating people. Many researches have shown that, in order to be a qualitative employee motivational means, the objectives should be as concrete and as exciting as possible, but not impossible, and always must be defined in collaboration with employees who will work to achieve them. Moreover, it is very important that the employee whose work is monitored should receive feedback about the quality of his work, about the extent of reaching the goals, acknowledgement for his work from the management and guidance to improve performance.

The second theoretical basis of employee performance management systems is represented by Vroom's theory of expectations, which shows that individuals will be motivated to invest maximum efforts in work if they believe they will be able to achieve the objectives that have been proposed to them. In addition, the individual's confidence that by achieving the proposed goals he will receive other rewards as well as what he considers valuable compensation for the effort invested in achieving those goals are also important.

Emphasizing the link between the organization's objectives and employee motivation through reward systems is largely dismissed in the research of Bevan and Thompson who have failed to find any correlation between the existence of the management system of employee performance and the performances achieved by the private sector organizations. Similarly, Armstrong and Baron in their research from 1998 found no correlation between the existence of these systems and the results of business organizations. Despite this, they mentioned that $77 \%$ of surveyed organizations said that their employee performance management systems are effective only to a certain extent. Research carried out in 2003 by Houldsworth $^{3}$, using in their research data from the major British companies, concluded that $68 \%$ of organizations rated their own employee performance management systems as very good.

Despite the fact that most scientists and top managers consider that employee performance management systems have become more sophisticated and more qualitative and therefore are much better accepted by employees, there is no clear evidence to support these statements. In the creation of employee performance management systems there are two basic concepts. They can be based on the work and the rewards that employees receive for their work. Despite some previous research showed that, on average, $85 \%$ of organizations have confirmed that there is a direct link between employee performance management system and salaries, the research of Armstrong and Baron showed that only $43 \%$ of the researched organizations argued that such a relationship exists.

It is interesting to note that, on the other hand, $82 \%$ of organizations that participated in the research have shown that they have some form of pay system based on results of performed work. Through this, the image of this research generated by the results becomes quite confusing. The only logical solution to this issue can be reflected in the fact that performance management is starting to be perceived as a process based on dialogue, mutual understanding, agreements and taking common obligations. It is seen to a much smaller extent as a 
means of evaluating employees with the purpose to determine the material and nonmaterial compensation for their work.

In contemporary business organizations, there are increasing the situations where all employees take more responsibility over their work performance management, most commonly through the development of group self-evaluation systems of work results during a whole year. In his research, Houldstworth said that $77 \%$ of organizations associate employees' salaries with evaluating the results of their work and that there is the impression that many organizations try to achieve simultaneously development and reward goals for their employees.

Finally, it is important to highlight the distinction between systems based on performance development and those based on performance measurement, because the practical experiences of performance developing management suggests that it is a process that is essentially motivational. It encourages line managers' dedication and bidirectional communication, thus providing the opportunity for roles and trainings to be in accordance with the specific business needs of each organization. On the other hand, if the focus is on measuring, the employee performance management systems can be considered as a means of evaluation, as an occasion for removing unwanted people and as a tool for enhancing control and achieving better work results and for payroll system management.

In Figure 1 we can see what a typical employee performance management system looks like. This system includes both aspects of development and reward.

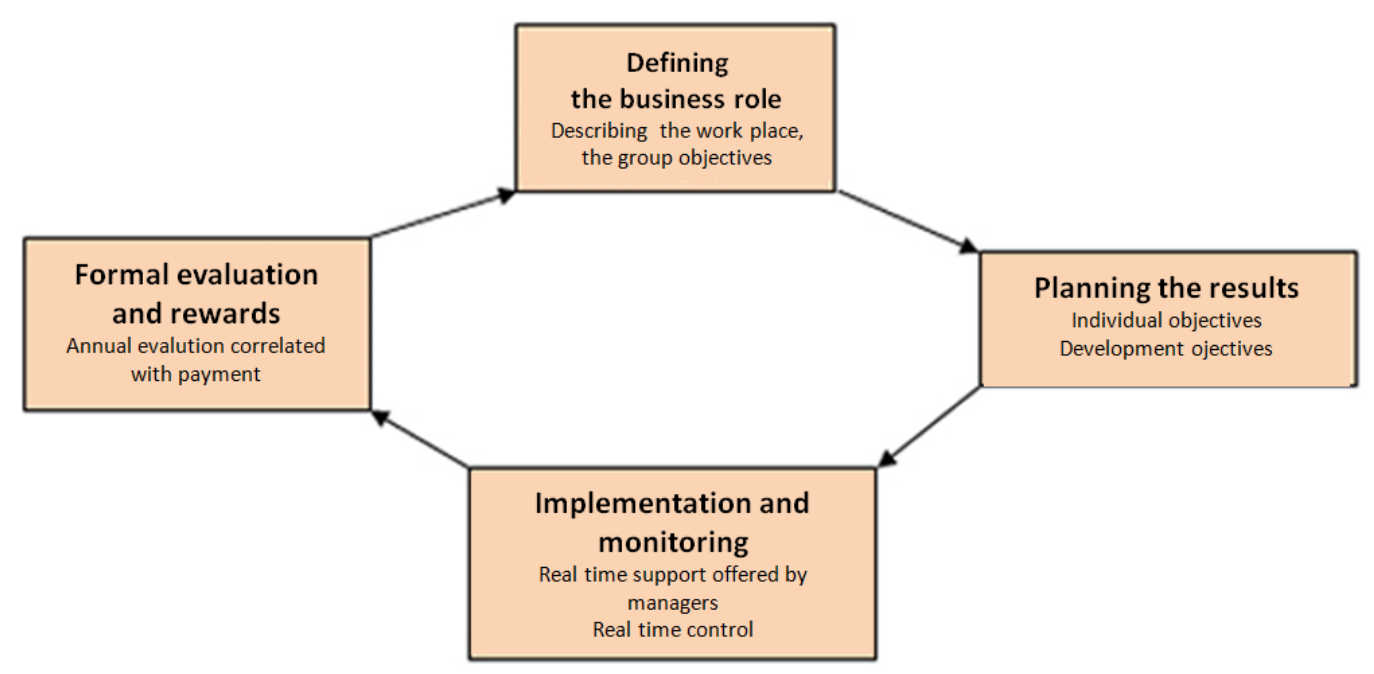

Figure 1: Stages in a typical employee performance management system

\section{References}

[1] Dragomiroiu R., Preda B.F., Hurloiu I.I., Mihai G., Organization management activity efficiency by planning internal audit, The 20th international scientific conference Knowledge-Based Organization, "Nicolae Bălcescu" Land Forces Academy Publishing House, ISSN 1843-6722, Sibiu, 2014, p. 51-54;

[2] Gribincea A., Imitational Models of the Innovation Development of the Country in Conditions of the Internationalization of the Economy, Chisinău-Sibiu: In Revista Economică. Nr. 5-6, 2008, 33 p. 
[3] Hurloiu I.I., Burtea E., Meruță A, Mihai G., Integrated supply and trading systems in the modern economy, The 20th international scientific conference Knowledge-Based Organization, "Nicolae Bălcescu" Land Forces Academy Publishing House, ISSN 18436722, Sibiu, 2014, p. 80-83;

[4] Hurloiu L.R., Burtea E., Hurloiu I.I., Meruță A., Preda B.F., Șerban M., Ștefan R.M. Documente contabile - management, control, audit, clasificare și securitate, Editura Print-Caro, Chișinău, 2014.

[5] Nonaka I., Hirotaka T., The Knowledge-Creating Company: HowJapanese Companies Create the Dynamics of Innovation. Oxford: Oxford University Press, USA, 1995. 304 p.

[6] Șerban M., Hurloiu L.R., Ștefan R.M., Hurloiu I.I., Situations reffering to the organization, classification and management of economic data, București, Annals of Spiru Haret University, 2015, vol 6, Issue 3,31 p. 